\title{
Bu open Living with HIV postdiagnosis: a qualitative study of the experiences of Nairobi slum residents
}

\author{
Eliud Wekesa, ${ }^{1}$ Ernestina Coast ${ }^{2}$
}

\begin{abstract}
To cite: Wekesa $\mathrm{E}$, Coast $\mathrm{E}$. Living with HIV postdiagnosis: a qualitative study of the experiences of Nairobi slum residents. BMJ Open 2013;3:e002399. doi:10.1136/bmjopen-2012002399
\end{abstract}

- Prepublication history for this paper are available online. To view these files please visit the journal online (http://dx.doi.org/10.1136/ bmjopen-2012-002399).

Received 23 November 2012 Revised 18 February 2013 Accepted 25 March 2013

This final article is available for use under the terms of the Creative Commons Attribution Non-Commercial 2.0 Licence; see http://bmjopen.bmj.com

${ }^{1}$ London School of

Economics-Social Policy,

London, UK

${ }^{2}$ Population Council,

Reproductive Health

Program, Nairobi, Kenya

Correspondence to

Dr Eliud Wekesa;

ewekesa@popcouncil.org

\section{ABSTRACT}

Objectives: To characterise the experiences of heterosexual men and women living with HIV postdiagnosis and explain these experiences in relation to their identity and sexuality.

Design: Qualitative study using in-depth interviews and a theoretically informed biographic disruption theory.

Setting: Interviews were conducted in two Nairobi slums (Kenya).

Participants: 41 HIV-infected heterosexual men and women aged 18 years or older.

Results: People living with HIV have divergent experiences surrounding HIV diagnosis. Postdiagnosis, there are multiple phases of identity transition, including status (non-)disclosure, and attempts at identity repair and normalcy. For some people, this process involves a transition to a new self-identity, incorporating both HIV and antiretroviral treatment (ART) into their lives. For others, it involves a partial transition, with some aspects of their prediagnosis identity persisting, and for others it involves a rejection of HIV identity. Those people who were able to incorporate HIV/AIDS in their identity, without it being disruptive to their biography, were pursuing safer sexual and reproductive lives. By contrast, those people with a more continuous biography continued to reflect their prediagnosis identity and sexual behaviour.

Conclusions: People living with HIV/AIDS (PLWHA) had to rework their sense of identity following diagnosis in the context of living in a slum setting. Men and women living with HIV in slums are poorly supported by health systems and services as they attempt to cope with a diagnosis of HIV. Given the availability of ART, health services and professionals need to support the rights of PLWHA to be sexually active if they want to and achieve their fertility goals, while minimising HIV transmission risk.

\section{INTRODUCTION}

Sub-Saharan Africa (SSA) is the region most affected by the HIV/AIDS pandemic, accounting for over $68 \%$ of the total global burden. ${ }^{1}$ A total of 1.6 million Kenyans are currently living with HIV and Kenyan adult

\section{ARTICLE SUMMARY}

Article focus

- Slum populations are under-researched, and very little empirical research examines the experiences of people living with HIV postdiagnosis.

- Impact of HIV postdiagnosis identity on sexual behaviour.

Key messages

- Men and women living with HIV in slums are poorly served by health services postdiagnosis.

- Health service provision and support does not incorporate the increasing needs of people living with HIV and AIDS to navigate their sexual and reproductive lives.

- The sexual behaviours of PLWHA are influenced by their HIV postdiagnosis identity transformation.

Strengths and limitations of this study

- The first in-depth study of the experiences of people living in slums following an HIV diagnosis in relation to their identity and sexuality.

- We did not include the perspectives of relevant stakeholders such as partners or policymakers.

HIV prevalence is estimated to be at $6.2 \%$, higher than that of the SSA region $(4.9 \%) .^{2}$

The introduction of antiretroviral therapy (ART) has improved the prognosis of HIV, with the potential to transform it into a chronic condition. Access to ART in low and middle income countries has expanded rapidly, with 6.6 million people now receiving treatment, nearly half of those eligible for treatment. ${ }^{1}$ Seventy-two per cent of Kenyan adults and children with advanced HIV infection receive ARV. ${ }^{3}$ With ART, the future life opportunities of PLWHA can change, including those related to sexuality and reproduction. ${ }^{4-6}$ However, research has focused on issues of access and adherence to ART for treatment effectiveness. ${ }^{7-9}$ Recently, evidence about the relationships between stigma and ARV availability and uptake has emerged from low-income settings. ${ }^{10}$ At the individual level, ARV adherence is negatively affected by 
stigma from partners, ${ }^{11-13}$ although self-stigma has been shown to decline in contexts of increasing access to treatment, ${ }^{14}$ and stigma changes over the life course. ${ }^{15}$ While the provision of ARV has the potential to reduce stigma about HIV/AIDS ${ }^{16}$ in a wide range of low-income contexts, ${ }^{17-19}$ this relationship is not universal. ${ }^{20}$ The relationship between ART and status disclosure to partner(s), family and community is also poorly understood, with the majority of evidence coming from highincome settings. ${ }^{21}$ Research from SSA suggests a distinctive pattern of disclosure that relies on third parties and intermediaries, especially religious leaders, as instruments of disclosure. ${ }^{22}$ The sexual health rights and needs of PLWHA remain under-researched and poorly understood, ${ }^{523} 24$ even though issues of stigma and disclosure are likely to be closely related to sexual behaviour postdiagnosis. There are policy concerns about treatment optimism, with an increase in riskier sexual behaviour as more people become aware that HIV/AIDS is a manageable condition with ART. ${ }^{25-28}$ Sexuality is a crucial element of being human and sexual health (pleasurable and safe sex) is an important component of overall health. ${ }^{29}$

Nearly three-quarters $(72 \%)$ of urban residents in SSA live in slums ${ }^{30}$ where single-room homes are densely packed. ${ }^{31}$ The poor health status of slum residents reflects on the poor environmental conditions and infrastructure, limited access to treatment and preventive health services as well as relying on poor quality and informal and regulated health services. ${ }^{32}$ Urban slums and their residents are an important, but underresearched, aspect of life in SSA. We undertook a qualitative study of the sexual and reproductive experiences and intentions of heterosexual men and women living with HIV in Nairobi slums.

\section{METHODS}

\section{Theoretical framework}

We organised and analysed our data using the theoretical concept of biographical disruption, ${ }^{33}$ to understand how HIV acts as a disruptive experience on an individual's life, social relations and identity. ${ }^{34-36}$ There are three components to biographic disruption-disruption of an individual's former behaviour or assumptions; changes in an individual's perceptions of self and an attempt to repair or change one's biography. Biographical disruption of HIV has been studied in the global North, and the extent to which it applies to PLWHA in other settings is much less well understood. $^{353738}$ Prior to the widespread availability of ART, evidence of the ways in which identity formation was affected by a HIV diagnosis focused on the mortality implications, ${ }^{35}$ stigma $^{39}$ and any subsequent disclosure. ${ }^{34}$ Earlier analyses tended to be based on quantitative questions in surveys ${ }^{34}$ with limited analytic insights. Recent analyses have incorporated evidence from qualitative and mixed methods studies and highlight the ways in which identity postdiagnosis has been used as a social and political force to improve treatment access. ${ }^{40}$ Research in Zambia, conducted pre-ART and post-ART roll-out, suggests that while ART makes disclosure easier, it also changes the context in which an individual discloses. ${ }^{41}$ Research into sexual behaviour post-HIV diagnosis in SSA has tended to focus on quantitative measures of sexual behaviour (number of partners, frequency of sex, concurrency, condom (non-) use ${ }^{42}$ with much of the research coming from South Africa, with some exceptions. ${ }^{434}$

\section{Study context}

Data for this study were collected from two slum communities (Korogocho and Viwandani) in Nairobi, Kenya. Housing conditions in these slums are temporary, typically single rooms constructed from mud, iron sheets, cardboard boxes and polythene. ${ }^{31}$ The settings are characterised by overcrowding, insecurity, poor sanitary conditions, poverty, high unemployment levels, poor amenities and infrastructure, limited access to preventative and curative services and reliance on poor quality, usually informal and unregulated health services. ${ }^{32} 45$ These conditions contribute to poor health outcomes for slum residents relative to other subpopulations in Kenya, including higher levels of mortality and morbidity, HIV prevalence, risky sexual behaviours, unmet need for contraception and unintended pregnancies. ${ }^{46-49}$

\section{Sampling and recruitment}

We analyse qualitative data collected as part of a larger mixed methods study of PLWHA (18 years and above) conducted in 2010. The study adopted a sequential design, with quantitative survey interviews $(n=513)$ followed by in-depth interviews with a subsample $(n=41)$ drawn from the survey. The quantitative sample size was determined on the basis of sample size calculations. ${ }^{50}$ Respondents were recruited from the Nairobi Urban Demographic and Health Surveillance System through quota sampling on the basis of seroprevalence ratios and sociodemographic characteristics in the study sites. ${ }^{49}$ Purposive selection of respondents for the qualitative interview was based on analyses of the survey data, and identification of a range of experiences. Key informant interviews $(\mathrm{n}=14)$ were conducted with health providers. Eight research assistants (RA) (four per site) were recruited for the quantitative survey, of which two per site were retained for the qualitative in-depth interviews. All RA had several years' experience of data collection in the study sites, were trained HIV/AIDS counsellors, and one RA was a PLWHA. Interviews were conducted in Kiswahili and the qualitative interviews were recorded, transcribed verbatim, translated into English and analysed using NVivo. ${ }^{51}$

\section{Ethical considerations}

We obtained written consent from all respondents and all interviews were conducted in a setting of the 
respondent's choice. Privacy in home settings in slums is difficult to achieve, and respondents were given the option of being interviewed in the offices of a local health organisation. A small grocery package was provided as compensation for each respondent. Approval for the study was granted by the Kenyan Medical Research Institute and the London School of Economics. Our analyses use pseudonyms for the presentation of data.

\section{RESULTS}

The sociodemographic characteristics of the qualitative study participants are summarised in table 1 .

We present detailed analyses of three typical case studies, purposively selected from the qualitative sample in order to draw out the complexities of biographical disruption following diagnosis with HIV.

By selecting three case studies, we contribute to a deeper understanding of the ways in which individual trajectories unfold postdiagnosis, acknowledging the complexity of biographical disruption. We selected these case studies to represent a range of sexual behaviour reported by the wider qualitative subsample (table 2).$^{52}$

\begin{tabular}{|c|c|}
\hline Characteristic & Per cent $(n=41)$ \\
\hline \multicolumn{2}{|l|}{ Slum of residence } \\
\hline Korogocho & 59 \\
\hline Viwandani & 41 \\
\hline \multicolumn{2}{|l|}{ Sex } \\
\hline Female & 56 \\
\hline Male & 44 \\
\hline \multicolumn{2}{|l|}{ Ethnicity } \\
\hline Kikuyu & 34 \\
\hline Luo & 24 \\
\hline Luyia & 20 \\
\hline Kamba & 15 \\
\hline Other & 7 \\
\hline \multicolumn{2}{|l|}{ Education } \\
\hline No schooling & 7 \\
\hline Primary & 66 \\
\hline Secondary and higher & 27 \\
\hline \multicolumn{2}{|l|}{ Marital status } \\
\hline Married/cohabiting & 41 \\
\hline Divorced/separated & 17 \\
\hline Widowed & 29 \\
\hline Never married & 12 \\
\hline \multicolumn{2}{|l|}{ Age } \\
\hline $18-29$ & 22 \\
\hline $30-39$ & 32 \\
\hline $40-49$ & 32 \\
\hline $50+$ & 15 \\
\hline \multicolumn{2}{|l|}{ Treatment status } \\
\hline Receiving ART & 56 \\
\hline Not receiving ART & 44 \\
\hline
\end{tabular}

\section{Reactions to a diagnosis of HIV}

HIV diagnosis is the first step in incorporating HIV/ AIDS into an individual's identity, challenging their identity as a healthy person. Most research on HIV testing in SSA focuses on its benefits, costs and barriers, ${ }^{53} 54$ with little understanding of people's experiences of having a test. ${ }^{55}$ Safari's narrative is typical of a health provider's response and management early in the epidemic

\section{INT: So how did you know your status?}

Safari: I kept going to Hospital. That is when I heard doctors saying things like HIV/AIDS and they started pointing fingers at me. Those days things were so bad; not like these days...He told me; you know, there is a disease that has come out. It does not have a cure. It is not known what kind of disease it is, and Safari, you have that disease.

\section{Diagnosis often occurred during a health crisis}

Jambo: I had a chest problem and when I went to hospital they told me that I had to be tested for HIV. I knew I had TB, but when I was tested for HIV...Oh no! aaayaai! I was surprised to be told that I was HIV+.

Being diagnosed with HIV/AIDS elicits multiple reactions, both negative (eg, shock) and positive (eg, relief). ${ }^{34} 56$ People struggled to grapple with the meaning of a positive test and its implication for their life. Their biographies were initially disrupted and needed reworking to accommodate HIV/AIDS. These initial emotions evolved and changed with time. Malaika's reaction was of distress and denial

\begin{abstract}
Malaika: I was very angry. I wished I was not alive because I saw myself as a dead person. I thought about killing myself. I wanted to kill my children but it was just that they were still very young. I did not suspect I was HIV positive because I did not go out with other men.
\end{abstract}

Safari feared being associated with prostitutes, a marginalised and stigmatised group

Safari: I will be put with the people who are cursed in life. A person called a prostitute is a cursed person. People would think that I came to Nairobi to be a prostitute. I hated myself. I took it as a curse.

Jambo's narrative involved putting on a brave face, a reaction that is rarely reported in studies of diagnosis reactions. ${ }^{34}{ }^{57}$ Jambo displayed a 'masculinity script ${ }^{58}$ by reporting himself to be brave, fearless and emotionless upon testing HIV positive

Jambo: I wasn't angry because I am a man. You are only scared if you are not a man. 
Table 2 Summary characteristics of three case study respondents

\begin{tabular}{|c|c|}
\hline Characteristics & Case study \\
\hline Sexually abstinent & $\begin{array}{l}\text { Malaika, female, } 29 \text { years, widowed, known HIV status for } 3 \text { years. } \\
\text { After her husband's death in } 2003 \text {, she was briefly 'inherited' by her } \\
\text { brother-in-law. This is a traditional practice involving a widow } \\
\text { becoming the de facto sexual partner of her dead husband's brother }\end{array}$ \\
\hline $\begin{array}{l}\text { Sexually active, monogamous relationship, } \\
\text { consistent use of condoms and/or contraception }\end{array}$ & $\begin{array}{l}\text { Safari, female, } 34 \text { years, currently cohabiting, known HIV status for } \\
15 \text { years }\end{array}$ \\
\hline $\begin{array}{l}\text { Sexually active, multiple partners, inconsistent use of } \\
\text { condoms and/or contraception }\end{array}$ & Jambo, male, 55 years, widower, known HIV status for 9 years \\
\hline
\end{tabular}

Diagnosis represented a first step in HIV identity formation, followed by decisions about whether to disclose their status.

\section{HIV status disclosure: to tell or not to tell}

Managing the flow of information about HIV status, including (non-) disclosure of HIV status is central to how people manage their identity postdiagnosis. Decisions to disclose evolve over time, encompassing a process beginning with non-disclosure and sometimes ending in forced disclosure

Safari: My mother was told but not by me. When you live with people in the house they will know something and they will start talking and word goes round. After all, my body betrayed me.

Safari's disclosure was articulated as subsequently driven by a desire to educate and inform others about $\mathrm{HIV} / \mathrm{AIDS}$, a disclosure motive that has also been documented in the $\mathrm{USA}^{59}$

Int: Why did you tell other relatives then?

Safari: ...So I wanted to educate them more about HIV/ AIDS. How you can get it and how to take care of it and how you can live with it.

Neither Malaika nor Jambo had disclosed their status to anyone beyond healthcare providers. A major barrier to their disclosure was fear of stigma and discrimination

Malaika: It is very difficult for me to disclose my status because people will start talking ill about me, they will not feel good when their children play together with my children and they will look down upon me. That is why I don't want to disclose it to any one and just want it to be my secret.

Jambo's explanation of his non-disclosure refers instead to issues of confidentiality

Jambo: How can I reveal matters affecting my body to anyone; that I have HIV? Why? Are they my doctor? Why should they know?

Key informant interviews reported similar negative social responses experienced by PLWHA
Nurse: I can remember a client...a man who came to me... he had been tested and we were just sharing with him. He told me when he went home and shared his HIV status with the wife, the wife packed and left.

Incorporation of HIV into people's identity is shaped by both individual reaction and the reaction of others and is a process of transition involving decisions about (non-) disclosure.

\section{Assimilation and resources for identity normalisation}

The third phase involves reorganisation and/or reconstruction of biographies towards some kind of normality, possibly different to that preceding HIV diagnosis, and requires resources for support and encouragement. ${ }^{60}$ The two main resources identified in our data include social capital and ART. Three major sources of social capital were identified as HIV support groups, government healthcare services and faith-based organisations. HIV support groups can provide confidential spaces where experiences and issues about HIV such as disclosure, sexuality and adherence are shared

Safari: We visit support groups where we learn a lot together. From there you just feel you belong to the society. You just feel you are [like HIV] 'negative' and not 'positive'. We are taught so many things about living positively with the disease.

Of our three in-depth case studies, only Safari had fully disclosed her status; she had assimilated her HIV status into her life and it had become central to her identity. For this group of people, social support groups played an integral role in creating and maintaining an HIV-positive identity, forming a biosociality to decipher biomedical information (eg, CD4 cell counts, viral loads and treatment side-effects), over and above individual clinic consultations. Safari developed her identity as a new 'career', 61 and formed a support group to provide social support for PLWHA and income generation activities (eg, selling beads and poultry farming)

Safari: I used to hate myself before, but now I am a very informed person living positively with HIV. I disclosed to many people and they began calling me mama ukimwi (mother AIDS), but I didn't mind. I have educated myself from newspapers and the television. I have a very 
big dream of changing the community. I chair a support group and have a dream of educating the community about HIV/AIDS. I overcame stigma and want to help other PLWHA.

Second, social capital from health workers is accessed postdiagnosis by PLWHA, regardless of their disclosure status. Community health workers are often the only sources of social capital for PLWHA who have not disclosed their status. PLWHA were assigned community healthcare workers (CHWs) who operate in the PLWHA's residential area, and are meant to meet at least once per week

Clinical Officer: They [CHWs] are the ones who deal mostly with these clients. They support them in the community so they can cope with the HIV situation. They are the ones helping us to do community outreaches, door to door training, door to door campaign on TB and HIV.

However, evidence from respondents suggested that this regular contact was rarely maintained, in part because community health workers often had multiple jobs in order to maximise their own incomes.

Third, faith-based social networks also play a role in helping people to shape their new identities, including the management of anxiety and depression ${ }^{62}$

Safari: Because I am not taking ART I know one day, God will heal me by faith. It has been 15 years since I knew my status but I have not taken any of these drugs.

Prayer and religiosity played a pivotal role in some PLWHA's lives, providing an essential source of spiritual support. Evidence from the UK suggests that religion can help to manage anxiety and depression postdiagnosis. ${ }^{62}$

ART can strengthen social relationships and selfidentity because it improves people's capacity to work, important for social and economic viability and validation, allowing people to play their societal role as a breadwinner, parent or adult. For many PLWHA, hope and uncertainty coexist, leading to contrasting and ambivalent views about ART, even among those individuals who have developed a positive identity

Safari: I should have started using the [ART] drugs, but I said no. The doctor was pushing me to start the drugs, but I refused.

Int: Why did you refuse?

Safari: Let me tell you, I fear those drugs. The thing that makes me fear them is the reactions they cause. I have seen the problems they cause to people. The swelling of the feet, then there is one that removes all the fat from the body and it brings to one side. You find one's breast has grown fat; you have a bad shape. That is why I fear them.
For many PLWHA, being HIV-positive is simply a medical label and not a defining feature of their identity

Int: So life goes on as usual?

Jambo: Yes ... people might say that I have HIV, but for me that is not important...My main problem is that I have no means to earn a living, I have many challenges. I am usually rained on in this house whenever it rains, but I cannot [afford to] migrate from here.

For those PLWHA who experienced a dissonance between their HIV status and their perceived health status, this tended to lead to the rejection of an HIV identity

Malaika: That thing [HIV diagnosis] is very painful that I even don't want to think about it. I don't even want be going to the NGOs to read those things about HIV/AIDS because I know I have it. I just want to stay ' $b u b u$ [dumb] style'.

Malaika had decided not to use ART because she had concerns about the requirement for good nutrition in order to be able to take the drugs

Int: Are you on ART?

Malaika: I am not on any treatment, I just stay like that... I don't see the need to use these drugs when I don't feel any pain in my body. In fact, I hear you need to eat well when you take those drugs and sometimes you don't have the means to buy food.

Lack of food as an issue in non-adherence to ART was highlighted by healthcare providers

Clinical Officer: We have experienced some clients who complain that they cannot take the drugs as instructed due to lack of food since the drugs are quite strong.

Our case studies illustrate the range of experiences around people's identities post-HIV diagnosis. Safari, with full disclosure, had started to make a career out of her HIV status, although she preferred to place her faith in religion, rather than ART, to maintain her health. Safari had completely assimilated a new HIV identity. Jambo, on the other hand, was motivated to adhere to ART in order that he would be able to work, but he had not disclosed his status to anyone outside the healthcare system. Jambo sought to maintain his biographic continuity, not allowing his identity to be affected by HIV diagnosis. For Malaika, an HIV diagnosis meant a biographical disruption, with neither incorporation of a new identity postdiagnosis nor adaptation of her identity. We explore how these different responses are associated with sexual behaviours.

Malaika's biographical disruption has implications for her sexual life 
Malaika: No, I have not had sex since I knew about my status. I lost sexual desire completely. I don't even long for a man... I actually hate them [men]. You know when a woman loses feeling? I don't have [sexual] feeling at all.

Those PLWHA who were able to incorporate HIV/ AIDS in their identity without it being disruptive to their biography were pursuing sexual lives. At the time of her interview, Safari was sexually active with a steady partner and reported consistent condom use

Safari: The man I am with, the first thing is, I am the person who will put the condom on for him. I do not want him to do it himself. Even if it is at night the lights have to be on, because a man is just a man, he might cut the condom and add me more viruses.

By contrast, Jambo's more continuous biography reflected his prediagnosis identity

INT: Did you use a condom during your last sex?

Jambo: Aaahi! How can I have sex with a woman while using a condom? Am I to fuck the condom or her vagina...so my blood gets into her?! Then I go and throw away my semen in the toilet, why? I don't want it, if it's a question of condoms, I would rather do away with a vagina because it will not benefit me in any way.

From Jambo's perspective, the need for sexual gratification involving sexual fluid exchange outweighs condom use. ${ }^{63}$

\section{DISCUSSION}

There are multiple complex responses to diagnosis with HIV, in an era of ART availability, set against a backdrop of life in a Nairobi slum. For some people, this process involves a transition to a new self-identity, incorporating both HIV and ART into their lives ${ }^{60}$; for others, it involves a partial transition, with some aspects of identity persisting, and others redefined. ${ }^{35} 3764$ Multiple phases of identity transition, including diagnosis, (non-) disclosure, positive living and attempts at repair and normalcy, play out in people's narratives and their sexual lives and futures.

PLWHA try to mobilise resources to help them deal with the diagnosis, ${ }^{35} 36$ including sources of social capital (eg, community health workers social groups, faith-based organisations) and ART. Such social networks provide support to mitigate psychological distress associated with an HIV diagnosis. ${ }^{65}$ Studies from elsewhere in SSA have documented a positive relationship between social capital and health ${ }^{66}$ and prayer/spirituality and quality of life among PLWHA. ${ }^{67}$ Emerging evidence also shows that the availability of social networks such as treatment partners, healthcare workers and social support groups facilitates retention in care and adherence to ART, ${ }^{38} 6668$ both associated with improved treatment outcomes.
The use of ART was a significant resource enabling PLWHA to regain positions as economically and socially productive and reproductive members of society, thereby fending off stigma. ${ }^{69} 70$ PLWHA face stigma in part because infection with HIV is associated with moral failures and a breach of social norms and taboos ${ }^{39}$ In the context of the high premium placed on parenthood, ${ }^{71}$ HIV posed a potential threat to peoples' identities as mothers and fathers. Resuming sex provides an opportunity for PLWHA to lead normal lives as well as to mitigate stigma and social disproval. ${ }^{72}$ However, the inherent social rewards of childbearing, in the context of poverty and limited access to social security, and its inherent risk of transmitting the virus are complex issues in reproductive decisions among PLWHA.

Sampling participants from the slum community is a major strength of our study. Most studies on PLWHA sample from HIV health services where participants are likely to have better access to services and to have been better informed about SRH services and HIV prevention than the general population of PLWHA. However, our interviews had a heterosexual and consensual sex focus and it is highly unlikely that respondents would volunteer same-sex or forced sex activities. Since these sexual identities and activities are stigmatised in Kenya, a different approach might have helped the research process, although their under-reporting might still persist. Information on sexual behaviour and fertility preferences were entirely based on self-reports using face-to-face interviews. Given the sensitive nature of these topics, there is likely to have been social desirability bias. Both men and women misreport their sexual behaviour $^{73}$ and respondents might be inclined to under-report their unsafe sexual behaviour. Although we took precautions to limit social desirability bias-such as training interviewers to create a climate of trust that allows free talk about such matters and using nonclinical community interviewers-its effect cannot be completely eliminated.

In spite of these limitations, this study contributes to the empirical literature on sexual and reproductive health of PLWHA in a poor setting, an under-researched topic. PLWHA experience life with HIV and face challenges around stigma, managing ART, negotiating sexual intimacy and reproduction. Our data show the need to address living with HIV/AIDS infection holistically, asking broad questions about the lived experience of PLWHA, paying attention to structural elements of poverty, gender and sociocultural norms, recognising PLWHA as sexual and reproductive human beings. Research in developing countries that have addressed the sexual behaviour of PLWHA has focused on risky behaviour mostly using quantitative data from surveys. ${ }^{74}$ Studies have considered the reproductive goals of PLWHA, ${ }^{75}$ suggesting that the sexual and reproductive behaviour of PLWHA should be understood by connecting sexuality to gender, reproductive goals and larger socioeconomic contexts. ${ }^{77} 78$ 
The effect of ART on sexual and reproductive behaviour is attracting research and policy attention following ART rollout in resource-poor settings. The findings of the few studies that have examined how treatment affects sexual and reproductive behaviour in such settings have produced mixed results, highlighting the need for a better evidence base. ${ }^{25} 7980$ There is a growing recognition of the need to support the rights of PLWHA to be sexually active, should they wish to be, while minimising HIV transmission risk, ${ }^{81}$ and this study is an effort in that direction. Meeting the sexual and reproductive health needs of PLWHA means more than just counselling on risk reduction. Psychosocial factors play a prominent role in sexual functioning, and diminished sexual interest and sexual abstinence are strongly associated with psychological distress, depression, anxiety and low quality of life, in addition to underlying ill-health represented by $\mathrm{CD} 4$ cell counts and duration or severity of illness. ${ }^{82}$ PLWHA could benefit from counselling around sexuality as a whole, not just risk reduction as is usually the case. Our findings speak to the need for interventions to help PLWHA to safely become sexually active if they want to. Because the process of incorporating HIV into an individual's identity is neither linear nor predictable, diagnosis presents an opportunity for healthcare providers to discuss these issues. Subsequent referrals for mental health services might, for example, become necessary depending on how individuals cope with their diagnosis

Acknowledgements We are grateful to the participants of the study for their time and contributions. We are grateful to the African Population and Health Research Centre for permission to sample from the Nairobi Urban Demographic Surveillance System.

Contributors EW and EC have provided administrative, technical or material support to the project, contributed to the study concept and design and performed the analysis and interpretation of the data. EW conducted the acquisition of the data as well as the drafting and critical revision of the manuscript. Both authors have read and approved the final manuscript.

Funding This work was supported by the Wellcome Trust grant number [078471/Z/05/A]

Competing interests None.

Ethics approval Kenyan Medical Research Institute (KEMRI) \& London School of Economics.

Provenance and peer review Not commissioned; externally peer reviewed.

Data sharing statement No additional data are available.

\section{REFERENCES}

1. UNAIDS. Global HIV/AIDS response: epidemic update and health sector progress towards Universal Access Progress Report 2011. Geneva, Switzerland: World Health Organization/United Nations United Nations Joint Programme on AIDS, 2011.

2. UNAIDS. UNAIDS report on the global AIDS epidemic. Geneva: UNAIDS, 2012:212.

3. NACC/NASCOP. Kenya AIDS epidemic update. Nairobi: National AIDS and STI control programme, 2011:144.

4. Birungi H, Undie CC, Aggleton P. Recent research on sexuality in East Africa. Cult Health Sex 2009;11:747-50.

5. Segurado AC, Paiva V. Rights of HIV positive people to sexual and reproductive health: parenthood. Reprod Health Matters 2007;15(29, Suppl 1):27-45.
6. WHO. Sexual and reproductive health of women living with HIV/ AIDS: guidelines on care, treatment and support for women living with HIV/AIDS and their children in resource-constrained settings. Geneva: World Health Organization, 2006.

7. Bartlett JA. Addressing the challenges of adherence. J Acquir Immune Defic Syndr 2002;29:S2-10.

8. Hardon A, Hodgkin C, Laing R. From access to adherence: the challenges of antiretroviral treatment. Studies from Botwana, Tanzania and Uganda. Geneva: World Health Organization, 2006.

9. Orrell C, Bangsberg R, Badri M, et al. Adherence is not a barrier to successful antiretroviral therapy in South Africa. AIDS 2003;17:1369-75.

10. Mahajan AP, Sayles J, Patel V, et al. Stigma in the HIV/AIDS epidemic: a review of the literature and recommendations for the way forward. AIDS 2008;22(Suppl 2):S67-79.

11. Nachega JB, Stein DM, Lehman DA, et al. Adherence to antiretroviral therapy in HIV-infected adults in Soweto, South Africa. AIDS Res Hum Retroviruses 2004;20:1053-6.

12. Dlamini PS, Wantland D, Makoae LN, et al. HIV stigma and missed medications in HIV-positive people in five African countries. AIDS Patient Care STDs 2009;23:377-87.

13. Weiser S, Wolfe W, Bangsberg D, et al. Barriers to antiretroviral adherence for patients living with HIV infection and AIDS in Botswana. J Acquir Immune Defic Syndromes 2003;34:281-8.

14. Roura M, Urassa M, Busza J, et al. Scaling up stigma? The effects of antiretroviral roll-out on stigma and HIV testing. Early evidence from rural Tanzania. Sex Transm Infect 2009;85:308-12.

15. Abrahams $\mathrm{N}$, Jewkes $\mathrm{R}$. Managing and resisting stigma: a qualitative study among people living with HIV in South Africa. J Int AIDS Soc 2012;15:1-11.

16. Preston-Whyte EM. Contexts of vulnerability: sex, secrecy and HIV/AIDS. Afr J AIDS Res 2003;2:89-94.

17. Abadía-Barrero $C E$, Castro $A$. Experiences of stigma and access to HAART in children and adolescents living with HIV/AIDS in Brazil. Soc Sci Med 2006;62:1219-28.

18. Cao X, Sullivan SG, Xu J, et al. Understanding HIV-related stigma and discrimination in a 'blameless' population. AIDS Educ Prev 2006;18:518-28.

19. Farmer P, Léandre F, Mukherjee SJ, et al. Community-based approaches to HIV treatment in resource-poor settings. Lancet 2001;358:404-9.

20. Maughan-Brown B. Stigma rises despite antiretroviral roll-out: a longitudinal analysis in South Africa. Soc Sci Med 2010;70:368-74.

21. Smith R, Rossetto K, Peterson BL. A meta-analysis of disclosure of one's HIV-positive status, stigma and social support. AIDS Care 2008;20:1266-75

22. Neville Miller A, Rubin DL. Factors leading to self-disclosure of a positive HIV diagnosis in Nairobi, Kenya: people living with HIV/AIDS in the Sub-Sahara. Qual Health Res 2007;17:586-98.

23. Cooper D, Moodley J, Zweigentha V, et al. Fertility intentions and reproductive health care needs of people living with HIV in Cape Town, South Africa: implications for integrating reproductive health and HIV care services. AIDS Behav 2009;13:38-46.

24. GNP+. Advancing the sexual and reproductive health and human rights of people living with HIV. Amsterdam: The Global Network of People Living with HIV/AIDS (GNP+), 2009.

25. Luchters S, Sarna A, Geibel S, et al. Safer sexual behaviors after 12 months of antiretroviral treatment in Mombasa, Kenya: a prospective cohort. AIDS Patient Care STDS 2008;22:587-94.

26. Remien R, Exner T, Morin S, et al. Medication adherence and sexual risk behavior among HIV-infected adults: implications for transmission of resistant virus. AIDS Behav 2007;11:663-75.

27. Crepaz N, Hart TA, Marks G. Highly active antiretroviral therapy and sexual risk behavior-a meta-analytic review. J Am Med Assoc 2004:292:224-36.

28. Kennedy C, O'Reilly K, Medley A, et al. The impact of HIV treatment on risk behaviour in developing countries: a systematic review. AIDS Care 2007;19:707-20.

29. De Ryck I, Van Laeken D, Nöstlinger C, et al. Sexual satisfaction among men living with HIV in Europe. AIDS Behav 2011:1-6.

30. UN-HABITAT. Slums of the world: the face of urban poverty in the new millenium? Global urban observatory. Nairobi: UN-Habitat, 2003.

31. Amuyunzu-Nyamongo $M$, Okeng'O L, Wagura $A$, et al. Putting on a brave face: the experiences of women living with HIV and AIDS in informal settlements of Nairobi, Kenya. AIDS Care 2007;19(1 Suppl 1):25-34.

32. Zulu E, Beguy D, Ezeh A, et al. Overview of migration, poverty and health dynamics in Nairobi City's slum settlements. J Urban Health 2011:88:185-99.

33. Bury M. Chronic illness as biographical disruption. Soc Health IIIn 1982;4:167-82 
34. Baumgartner LM. The incorporation of the HIV/AIDS identity into the self over time. Qual Health Res 2007;17:919-31.

35. Carricaburu D, Pierret J. From biographical disruption to biographical reinforcement: the case of HIV-positive men. Sociol Health IIIn 1995; 17:65-88

36. Williams S. Chronic illness as biographical disruption or biographical disruption as chronic illness? Reflections on a core concept. Sociol Health IIIn 2000;22:40-67.

37. Ciambrone De. Illness and other assaults on self: the relative impact of HIV/AIDS on women's lives. Sociol Health IIIness 2001;23:517-40.

38. Wouters E, Van Damme W, Van Loon F, et al. Public-sector ART in the free state province, South Africa: community support as an important determinant of outcome. Soc Sci Med 2009;69:1177-85.

39. Parker R, Aggleton P. HIV and AIDS-related stigma and discrimination: a conceptual framework and implications for action. Soc Sci Med 2003;57:13-24.

40. Levy JM, Storeng KT. Living positively: narrative strategies of women living with HIV in Cape Town, South Africa. Anthropol Med 2007:14:55-68.

41. Frank $E$. The relation of HIV testing and treatment to identity formation in Zambia. Afr J AIDS Res 2009:8:515-24.

42. Kiene SM, Christie S, Cornman DH, et al. Sexual risk behaviour among HIV-positive individuals in clinical care in urban KwaZulu-Natal, South Africa. AIDS 2006;20:1781-4.

43. Moatti J-P, Prudhomme J, Traore C, et al. Access to antiretroviral treatment and sexual behaviours of HIV-infected patients aware of their serostatus in Côte d'Ivoire. AIDS 2003;17(Suppl 3):S69-77.

44. Pettifor A, MacPhail C, Corneli A, et al. Continued high risk sexual behavior following diagnosis with acute HIV infection in South Africa and Malawi: implications for prevention. AIDS Behav 2011;15:1243-50.

45. APHRC. Population and health dynamics in Nairobi's informal settlements. Nairobi: African Population and Health Research Center, 2002.

46. Madise NJ, Ziraba AK, Inungu J, et al. Are slum dwellers at heightened risk of HIV infection than other urban residents? Evidence from population-based HIV prevalence surveys in Kenya. Health Place 2012;18:1144-52.

47. Montgomery M. Urban poverty and health in developing countries. Popul Bull 2009;64:1-20.

48. Zulu E, Dodoo F, Ezeh A. Sexual risk-taking in the slums of Nairobi, Kenya, 1993-98. Popul Stud (Camb) 2002;56:311-23.

49. Madise NJ, Ziraba A, Inungu J, et al. Are slum dwellers at heightened risk of HIV infection than other urban residents? Evidence from population-based HIV prevalence surveys in Kenya Health Place 2012;18:1144-52.

50. Magnani R. Sampling guide. Arlington, VA: MPACT Food Security and Nutrition Monitoring Project, 1997.

51. Braun V, Clarke V. Using thematic analysis in psychology. Qual Res Psychol 2006;3:77-101.

52. Ivankova NV, Creswell JW, Stick SL. Using mixed-methods sequential explanatory design: from theory to practice. Field Methods 2006;18:3-20.

53. Kaler A, Watkins S. Asking God about the date you will die: HIV testing as a zone of uncertainty in rural Malawi. Demogr Res 2010;23:905-32.

54. Gersovitz M. HIV testing: principles and practice. World Bank Res Obs 2011;26:1-41.

55. Obermeyer CM, Osborn M. The utilization of testing and counseling for HIV: a review of the social and behavioral evidence. Am J Public Health 2007;97:1762-74.

56. Baumgartner LM, David KN. Accepting being poz: the incorporation of the HIV identity into the self. Qual Health Res 2009;19:1730-43.

57. Ciambrone De. Women's experiences with HIVIAIDS: mending fractured selves. Binghamton, NY: The Haworth Press, 2003.

58. Mahalik JR, Good GE, Englar-Carlson M. Masculinity scripts, presenting concerns, and help seeking: implications for practice and training. Prof Psychol Res Pract 2003;34:123-31.

59. Derlega VJ, Winstead BA, Greene E, et al. Reasons for HIV disclosure/nondisclosure in close relationships: testing a model of HIV-disclosure decision making. J Soc Clin Psychol 2004;23:747-67.
60. Russell S, Seeley J. The transition to living with HIV as a chronic condition in rural Uganda: working to create order and control when on antiretroviral therapy. Soc Sci Med 2010;70:375-82.

61. Bartos M, McDonald K. HIV as identity, experience or career. AIDS Care 2000;12:299-306.

62. Anderson M, Elam G, ljeoma I, et al. Coping with HIV: Caribbean people in the United Kingdom. Qual Health Res 2009;19:1060-75.

63. Coast $\mathrm{E}$. Wasting sperm: the Maasai context of condom use in Northern Tanzania. Cult Health Sex 2007;9:387-401.

64. Wilson S. 'When you have children, you're obliged to live'1: motherhood, chronic illness and biographical disruption. Sociol Health IIIn 2007;29:610-26.

65. Kalichman SC, DiMarco M, James J, et al. Stress, social support and HIV-status disclosure to family and friends among HIV-positive men and women. J Behav Med 2003;26:315-32.

66. Pronyk PM, Harpham T, Morison LA, et al. Is social capital associated with HIV risk in rural South Africa? Soc Sci Med 2008;66:1999-2010.

67. Friend-du Preez N, Peltzer K. HIV symptoms and health-related quality of life prior to initiation of HAART in a sample of HIV-positive South Africans. AIDS Behav 2010;14:1437-47.

68. Binagwaho A, Ratnayake N. The role of social capital in successful adherence to antiretroviral therapy in Africa. PLoS Med 2009;6:e18.

69. Campbell C, Skovdal M, Madanhire C, et al. 'We, the AIDS people...': how antiretroviral therapy enables Zimbabweans living with HIV/AIDS to cope with stigma. Am J Public Health 2011:101:1004-10.

70. Castro A, Farmer P. Understanding and addressing AIDS-related stigma: from anthropological theory to clinical practice in Haiti. $A m$ $J$ Public Health 2005;95:53-9.

71. Awiti Ujiji O, Ekström A, llako F, et al. 'I will not let my HIV status stand in the way.' Decisions on motherhood among women on ART in a slum in Kenya-a qualitative study. BMC Womens Health 2010;10:1-10.

72. Smith DJ, Mbakwem BC. Antiretroviral therapy and reproductive life projects: mitigating the stigma of AIDS in Nigeria. Soc Sci Med 2010;71:345-52.

73. Buvé A, Caraël R, Hayes RJ, et al. Multicentre study on factors determining differences in rate of spread of HIV in sub-Saharan Africa: methods and prevalence of HIV infection. AIDS 2001;15:S5-S14.

74. Bateganya M, Colfax G, Shafer LA, et al. Antiretroviral therapy and sexual behavior: a comparative study between antiretroviral-naive and -experienced patients at an urban HIV/AIDS care and research center in Kampala, Uganda. AIDS Patient Care STDS 2005;19:760-8.

75. Cooper D, Harries J, Myer L, et al. 'Life is still going on': reproductive intentions among HIV-positive women and men in South Africa. Soc Sci Med 2007:65:274-83.

76. Myer L, Morroni C, Rebe K. Prevalence and determinants of fertility intentions of HIV-infected women and men receiving antiretroviral therapy in South Africa. AIDS Patient Care STDS 2007;21:278-85.

77. Laher F, Laher F, Strathdee SA, et al. A qualitative assessment of decisions affecting contraceptive utilization and fertility intentions among HIV-positive women in Soweto, South Africa. AIDS Behav 2009;13:47-54

78. Persson A, Richards W. Vulnerability, gender and 'proxy negativity': women in relationships with HIV-positive men in Australia. Soc Sci Med 2008:67:799-807.

79. Kaida A, Laher F, Strathdee SA, et al. Childbearing intentions of HIV-positive women of reproductive age in Soweto, South Africa: the influence of expanding access to HAART in an HIV hyperendemic setting. Am J Public Health 2011;101:350-8.

80. Sarna A, Chersich M, Okal J, et al. Changes in sexual risk taking with antiretroviral treatment: influence of context and gender norms in Mombasa, Kenya. Cult Health Sex 2009;11:783-97.

81. Kaida A, Bangsberg D, Gray G, et al. Editorial: introduction to the supplement on HIV, HAART, and fertility in sub-Saharan Africa. AIDS Behav 2009;13:1-4.

82. Florence $\mathrm{E}$, Schrooten $\mathrm{W}$, Dreezen $\mathrm{C}$, et al. Prevalence and factors associated with sexual dysfunction among HIV-positive women in Europe. AIDS Care 2004;16:550-7. 


\section{Correction}

Wekesa E, Coast E. Living with HIV postdiagnosis: a qualitative study of the experiences of Nairobi slum residents. BMJ Open 2013;3:e002399. The affiliations in this paper have been mixed up. The correct affiliations are as follows:

Dr Eliud Wekesa - Population Council, Reproductive Health Program, Nairobi, Kenya. Dr Ernestina Coast - London School of Economics, Social Policy, London, UK.

BMJ Open 2013;3:e002399corr1. doi:10.1136/bmjopen-2012-002399corr1 